\title{
Phenotypic variation in Actinobacillus actinomycetemcomitans during laboratory growth: implications for virulence
}

\author{
Daniel H. Fine, ${ }^{1}$ David Furgang, ${ }^{1}$ Helen C. Schreiner, ${ }^{1}$ Paul Goncharoff, ${ }^{1}$ \\ Jon Charlesworth, ${ }^{4}$ Ghazi Ghazwan, ${ }^{2}$ Patricia Fitzgerald-Bocarsly ${ }^{3}$ \\ and David H. Figurski ${ }^{5}$
}

Author for correspondence: Daniel H. Fine. Tel: +1 973972 3278. Fax: +1 9739720045 e-mail: finedh@umdnj.edu

1,2,3 Department of Oral Pathology and Biology', Department of Periodontology 2 and Department of Pathology 3 , University of Medicine and Dentistry of New Jersey, Newark, NJ, USA

4 Electron Microscopy Core Facility, Mayo Clinic, Rochester, Minnesota, USA

5 Department of Microbiology, College of Physicians \& Surgeons, Columbia University, New York, NY, USA
This study examined alteration of specific virulence traits associated with phenotypic changes seen when a low-passage disease-associated and well maintained parent strain of Actinobacillus actinomycetemcomitans was compared to a laboratory-grown spontaneous variant/mutant. Clinical isolates of A. actinomycetemcomitans recovered from periodontitis patients typically grow as rough, adherent colonies on primary culture but undergo transformation to smooth, non-adherent colonies following repeated passage in vitro. The relationship of these phenotypic changes to the virulence of the organism or to the processes that underlie this transformation are not understood. A fresh clinical isolate, designated strain CU1000, was obtained from the first molar site of a patient with classical signs of localized juvenile periodontitis and used as the parent strain to study virulence-related phenotypes. Following several passages of CU1000 on selective agar, a spontaneous variant that demonstrated smooth, opaque, non-adherent colonies was isolated and designated strain CU1060. This study compared the properties of these two strains with respect to colony morphology, autoaggregation, surface appendages, adherence to saliva-coated hydroxyapatite (SHA), LPS chemotype and activity, induction of fibroblast proteinase activity and antigenic properties. CU1000 demonstrated rough, raised, star-positive colonies which upon electron microscopic examination revealed the presence of large, flexible, bundled fibrils. In addition, CU1000 showed adherence to SHA, several unique protein antigens and elevated endotoxin and fibroblast proteinase activity. CU1060, on the other hand, showed minimal adherence to SHA and fewer reactive proteins compared to the fresh clinical isolates. This strain formed smooth, opaque colonies on agar, showed minimal fibril formation and limited endotoxin and fibroblastproteinase-inducing activity. These findings demonstrate that clinical isolates of A. actinomycetemcomitans undergo significant virulence-reducing phenotypic alterations during in vitro passage and support the need to study this organism in its clinical form.

Keywords: A. actinomycetemcomitans, virulence, phenotype, clinical isolate

\section{INTRODUCTION}

Actinobacillus actinomycetemcomitans, a Gram-negative, capnophilic coccobacillus capable of causing severe

Abbreviations: APMA, aminophenylmercuric acetate; FSF, foreskin fibroblasts; S(T)EM, scanning (transmission) electron microscopy; (S)HA, (salivacoated) hydroxyapatite. infections in humans (Kaplan et al., 1989), has been implicated as a primary aetiologic agent of localized juvenile periodontitis (Newman et al., 1976). In addition, A. actinomycetemcomitans has been isolated from infections of the heart (Anolik et al., 1981), brain (Garner, 1979), thyroid (Burgher et al., 1973), lungs (Yuan et al., 1992), bone (Muhle et al., 1979) and urinary tract (Townsend \& Gillenwater, 1969). Several virulence 
factors associated with this bacterium have been shown to affect leukocytes, monocytes (Baehni et al., 1979; Taichman et al., 1980; Tsai et al., 1979), epithelial cells (Kamen, 1983) and fibroblasts (Shenker et al., 1982; Stevens et al., 1983). To date, the only putative virulence factor that has been well characterized at the genetic level is the $116 \mathrm{kDa}$ leukotoxin protein, which lyses human and primate polymorphonuclear leukocytes and is encoded by the lktCABD operon (Kraig et al., 1990; Lally et al., 1989).

Fresh isolates of A. actinomycetemcomitans produce rough, star-positive, adherent colonies. Cells from rough colonies adhere to the walls of the culture vessel when grown in broth and have been reported to possess fimbriae (Inouye et al., 1990; Rosan et al., 1988; Scannapieco et al., 1987). Each of these studies and others have reported that prolonged in vitro growth of these isolates results in transformation to a smooth, non-adherent, colony type that fails to demonstrate fimbriae (Wyss, 1989). Since clinical isolates routinely exhibit a rough, adherent phenotype, it seems reasonable to conclude that these characteristics contribute to the ability of the organism to colonize the oral cavity (Rosan et al., 1988; Slots, 1982a; Zambon, 1985). However, the inability to preserve the stability of the these 'attachment-related' traits coupled with the autoaggregating or clumping characteristics of fresh isolates has made it difficult to study clinically relevant forms of $A$. actinomycetemcomitans. Consequently, much of the research related to A. actinomycetemcomitans has been performed using frequently grown laboratory strains, such as Y4 (ATCC 43718), which appears to have lost many of the 'attachment or surface-related' features of fresh clinical isolates (Inouye et al., 1990; Rosan et al., 1988; Scannapieco et al., 1987). Laboratory growth of a number of other pathogenic strains, such as Escherichia coli (Guerina et al., 1983), Neisseria gonorrhoeae (Kellogg et al., 1963), Shigella flexneri (Duguid \& Gillies, 1957) and Vibrio cholerae El Tor (Finkelstein et al., 1979), have resulted in a similar loss of diseaseassociated virulence traits.

Several strains of $A$. actinomycetemcomitans were isolated from patients with juvenile periodontitis. One specific strain (CU1000) obtained from a patient with a classical case of localized juvenile periodontitis was used for detailed analysis. This strain displayed the rough, star-positive colony morphology expected of fresh clinical isolates. We found this phenotype to be relatively stable when the organism was grown on solid medium, although spontaneous variants exhibiting a smooth, non-adherent phenotype emerged at a low frequency. One such variant (CU1060) was isolated and retained for further study. Both CU1000 and its smooth variant CU1060 proved to be serotype b (Saarela et al., 1992) and showed leukotoxin promoter regions similar to $A$. actinomycetemcomitans 652 (Brogan et al., 1994; Goncharoff et al., 1993). All experiments reported herein are based on the isolation and characterization of a fresh clinical strain of A. actinomycetemcomitans (CU1000) and a variant (CU1060) that arose spontaneously during growth of this strain. The purpose of this study was to determine the difference in some biological properties associated with virulence when comparing this wildtype rough-fimbriated strain of A. actinomycetemcomitans to its smooth, non-fimbriated spontaneous mutant strain.

\section{METHODS}

Media and growth conditions for bacteria. A. actinomycetemcomitans was maintained on a base medium, designated AAGM agar, which consisted of $40 \mathrm{~g}$ Trypticase soy agar $\mathrm{l}^{-1}$ (Fisher) and $6 \mathrm{~g}$ yeast extract $\mathrm{l}^{-1}$ (Sigma) supplemented with $0.4 \%$ sodium bicarbonate (Sigma) and $0.8 \%$ dextrose (Mandell \& Socransky, 1981; Slots, 1982b). Trypticase soy broth $\left(30 \mathrm{~g} \mathrm{l}^{-1}\right)$ was substituted for agar to make AAGM broth. A. actinomycetemcomitans laboratory strain Y4 (ATCC 43718) was used. Methods for isolation and maintenance of clinical isolates of CU1000 are described below.

Porphyromonas gingivalis W-50 (ATCC 53978) was grown in medium consisting of $\left(\mathrm{g} \mathrm{l}^{-1}\right)$ Trypticase peptone (15), yeast extract (5), $\mathrm{NaCl}(2 \cdot 5)$, dextrose $(2 \cdot 5)$ and cysteine/ $\mathrm{HCl}(0 \cdot 65)$ supplemented with $1 \mathrm{~g}$ haemin $\mathrm{l}^{-1}$ and $100 \mathrm{mg}^{\circ}$ menadione $\mathrm{l}^{-1}$. The organism was grown at $37^{\circ} \mathrm{C}$ in anaerobic conditions for $3 \mathrm{~d}$.

E. coli $\mathrm{INVF}^{\prime} \alpha$ was grown on an LB agar plate consisting of $\left(\mathrm{gl}^{-1}\right)$ Bacto tryptone (10; Difco), yeast extract (5) and $\mathrm{NaCl}(5)$ with the addition of $15 \mathrm{~g}$ agar $\mathrm{l}^{-1}$ if needed. The organism was grown at $37^{\circ} \mathrm{C}$ in air for $24 \mathrm{~h}$.

Isolation of $\boldsymbol{A}$. actinomycetemcomitans strains. The primary A. actinomycetemcomitans strain used in this study was obtained from a 13 year old, medically healthy, AfricanAmerican female patient who manifested classical signs of localized juvenile periodontitis (Newman et al., 1976). Initial isolation of $A$. actinomycetemcomitans was accomplished on AAGMBV agar, consisting of AAGM with the addition of $75 \mu \mathrm{g}$ bacitracin $\mathrm{ml}^{-1}$ (Sigma) and $5 \mu \mathrm{g}$ vancomycin $\mathrm{ml}^{-1}$ (Sigma) (Slots, 1982b). Plates were incubated at $37^{\circ} \mathrm{C}$ in an atmosphere of $5 \% \mathrm{CO}_{2}$ for $3-5 \mathrm{~d}$. The mesial proximal surface of the first molar, chosen as the sampling site, demonstrated a periodontal pocket of 6-7 $\mathrm{mm}$ with early evidence of bone loss on radiographic examination. Following isolation of the site with cotton rolls, supragingival plaque was removed with a dental scaler and medium absorbent paper points (Johnson \& Johnson) were inserted into the subgingival pocket for $10 \mathrm{~s}$. Paper point samples were removed, placed into Eppendorf tubes containing $200 \mu$ l reduced transport medium (Syed \& Loesche, 1972), subjected to $30 \mathrm{~s}$ vortex agitation, immediately streaked onto AAGMBV agar and incubated for $3-5 \mathrm{~d}$ at $37^{\circ} \mathrm{C}$ in an atmosphere of $5 \% \mathrm{CO}_{2}$. Colonies of approximately 1-2 $\mathrm{mm}$ diameter, having a rough surface texture, displaying an internal star-like configuration when observed by transmitted light microscopy and leaving a footprint in the agar after removal were classified as typical clinical isolates (Slots, 1982a). These isolates were found to be Gram-negative, catalase-positive and were confirmed as $A$. actinomycetemcomitans by PCR analysis (Goncharoff et al., 1993). One such colony was subcultured on agar and named CU1000. Colonies fitting this description were removed from the agar with a punch, placed in AAGM broth containing $10 \%$ DMSO and frozen at $-80{ }^{\circ} \mathrm{C}$ for future use. When these isolates were thawed, inoculated and grown in AAGMBV broth, they adhered avidly to the test tube wall. 
CU1060 originated on an AAGMBV agar plate as a spontaneous, smooth-textured variant of CU1000. When grown in broth, cells derived from this colony no longer adhered to the wall of the test tube. After restreaking on agar, these colonies were smooth, creamy, devoid of an internal star and remained catalase-positive. Cells from these colonies were Gramnegative and were confirmed as A. actinomycetemcomitans by PCR analysis. A single well isolated colony with these characteristics was restreaked and stored as described for CU1000. PCR was used to check the identity of these variant strains throughout the study.

Preparation of cells from rough strains. Single colonies were passed from plate to plate and confirmed as $A$. actinomycetemcomitans as described above. In all cases strains were maintained from single well isolated colonies. The thick part of a streak taken from a single well isolated plate-grown colony was used to promote more rapid growth of cells in broth. In this manner, a heavy streak was used as the inoculum for $200 \mathrm{ml}$ AAGMBV broth in a $750 \mathrm{ml}$ plastic Falcon Tissue Culture Flask (Fisher). Flasks were placed on their sides and incubated for $3 \mathrm{~d}$ at $37^{\circ} \mathrm{C}$. After the broth was decanted to remove any non-adherent cells, the walls of the flask were washed thoroughly three times by vigorous shaking in the presence of $50 \mathrm{ml} 0.15 \mathrm{M}$ PBS $(0.85 \%$ PBS, pH $7 \cdot 4$; Sigma). Following washing, adherent cells were scraped from the walls of the flask with a Falcon cell scraper 3087 (Fisher), suspended in $20-30 \mathrm{ml}$ PBS, pelleted at $8000 \mathrm{~g}$ for $10 \mathrm{~min}$ and resuspended in $2 \mathrm{ml}$ PBS to an approximate $\mathrm{OD}_{561}$ of 0.8 , equivalent to a cell concentration of $1 \times 10^{8}$ cells ml $^{-1}$ (stock suspension). These cells were plated on AAGMBV agar and confirmed as A. actinomycetemcomitans by visual, biochemical and PCR methods. For all assays, cells were subjected to sonication at low power output for $15 \mathrm{~s}$ with a Branson sonifier to allow for assessment of $\mathrm{OD}_{560}$.

Preparation of cells from smooth strains. Single well isolated colonies of CU1060 were passed from plate to plate and a single colony grown on AAGMBV agar was used as the inoculum for $500 \mathrm{ml}$ AAGMBV broth. After $3 \mathrm{~d}$ growth at $37^{\circ} \mathrm{C}$, the broth culture was pelleted by centrifugation at $8000 \mathrm{~g}$ for $10 \mathrm{~min}$. Pelleted cells were washed twice, resuspended in $2 \mathrm{ml} \mathrm{PBS}$ and adjusted to an approximate $\mathrm{OD}_{560}$ of $0 \cdot 8$. Confirmation of cell identity was made by biochemical and PCR methods.

Electron microscopy. Bacterial cells used for microscopic examination were obtained from both solid and broth cultures. In the case of agar-plate-derived cells, distinct, well isolated colonies were used for microscopy. For negative staining, the colonies were picked from plates, dispersed and resuspended in $1 \%$ phosphotungstic acid adjusted to $\mathrm{pH} 7 \cdot 2$ with $1 \mathrm{M} \mathrm{NaOH}$. Broth-grown cells were incubated overnight, washed, pelleted and stained, or, in some instances, washed, pelleted and resuspended in $0.85 \%$ PBS $/ 0.01 \%$ sodium azide (Sigma), pH 7.4, prior to negative staining. Standard methods were used for transmission (Rosan et al., 1988) and scanning electron microscopic observation (Holt et al., 1980). The identity of the specimens was not known during electron microscopic examination to preclude preferential selection of structures associated with a particular strain.

Autoaggregation of clinical and laboratory strains. For autoaggregation, $1 \mathrm{ml}$ samples of the adjusted stock suspensions of CU1000 and CU1060 were placed into five $10 \times 75 \mathrm{~mm}$ borosilicate test tubes (Fisher). Sonication was required to dissociate clumps of cells in suspension, which occurred in the case of CU1000. Dispersion was accomplished with a Branson Sonicator micro tip at a duty cycle setting of
$50 \%$ set at an output value equal to $1 \cdot 5$. Each tube was subjected to one sonication time of $5,15,30,45$ or $60 \mathrm{~s}$. After dispersion was achieved and the cell suspension appeared homogeneous, the formation of aggregates could be assessed over time. Formation of aggregates in each tube was recorded as the time at which clumps of cells settled to the bottom of the tube, with no turbidity visible in the broth. Cell viability was checked prior to and after each sonication period by plating and counting. The goal of these experiments was to determine the sonication time required for uniform dispersion of cells so that aggregation would not confound the assessment of cell concentration in the biological assays described below.

Adherence to saliva-coated hydroxyapatite (SHA). In adherence studies, $1 \mathrm{ml}$ of the adjusted stock suspension of CU1000 and CU1060 were used to achieve an approximate $\mathrm{OD}_{560}$ of $0 \cdot 9$. To break up clumps, cells were sonicated for $15 \mathrm{~s}$ at low power output as described. For attachment assays, $50 \mathrm{mg}$ hydroxyapatite (HA) beads $(\mathrm{BDH})$ were placed in Eppendorf tubes, washed and equilibrated in buffered $\mathrm{KCl}$ (0.05 mM KCl, $1 \mathrm{mM}$ potassium phosphate, pH 6.0, $1 \mathrm{mM}$ $\mathrm{CaCl}_{2}, 0 \cdot 1 \mathrm{mM} \mathrm{MgCl}_{2}$ ) overnight (Clark et al., 1978). Whole unstimulated saliva was collected repeatedly from five periodontally and medically healthy adults in wide mouth plastic tubes to achieve a minimum pooled volume of $40 \mathrm{ml}$. Salivary collections were separated into aliquots, frozen, thawed when needed and then clarified by centrifugation for $30 \mathrm{~min}$ at $10000 \mathrm{~g}$. Immediately after centrifugation, the clear supernate resulting from this procedure was used in experiments as described below. Clarified saliva $(1 \mathrm{ml})$ was added to $50 \mathrm{mg}$ HA beads contained in Eppendorf tubes. The saliva was equilibrated with the $\mathrm{HA}$ beads for $2 \mathrm{~h}$ at $37^{\circ} \mathrm{C}$ after which the SHA beads were subjected to centrifugation at $12000 \mathrm{~g}$ for $10 \mathrm{~min}$. Beads were then washed three times with buffered $\mathrm{KCl}$ prior to reaction with bacteria. CU1000 or CU1060 (200 $\mu \mathrm{l}$ of each culture) were added to 32 Eppendorf tubes, 16 each. Cells and SHA beads were incubated for $2 \mathrm{~h}$ at $37^{\circ} \mathrm{C}$ with slow rotation. After incubation, the beads were washed three times in buffered $\mathrm{KCl}$ and each bead/bacterial complex was then subjected to sonication at low power impulse using a Branson Sonicator to remove cells attached to the SHA for quantification. Eight sonication times were used $(0,2,5,10,20,30$, $45,60 \mathrm{~s}$ ), one time for each pair of tubes of each strain. The longer sonication times were required to dislodge the more avidly bound cells. After each sonication period, the beads were allowed to settle to the bottom of the tube $(\sim 2 \mathrm{~min})$. One hundred microlitres of the supernatant was removed from each tube and serial dilutions of the supernatants were plated on AAGMBV agar for quantification of colonies. Plates were incubated for $72 \mathrm{~h}$ at $37^{\circ} \mathrm{C}$ and total c.f.u. $\mathrm{ml}^{-1}$ for each tube was plotted against the time of sonication. Preliminary experiments indicated that cells detached after $30 \mathrm{~s}$ sonication in a highly reproducible manner and that $60 \mathrm{~s}$ sonication had no effect on cell viability. Estimation of the quantity of unbound cells (UC) was extrapolated from counts found in the supernatant fluid immediately prior to the sonication cycle (zero time). Maximally bound cells (BC) were calculated by subtracting the number of cells found in the supernatant after $60 \mathrm{~s}$ sonication from counts found at zero time. Avidity, or strength of binding to SHA, was related to the duration of time of sonication required to reach the point at which no additional cells could be removed from the beads. The longer the sonication time required to achieve this equilibrium, the greater the avidity of the cells in question. In all cases binding of CU1000 was compared to that of CU1060. Experiments were performed three times. BSA-coated and uncoated HA were used as controls. 
Preparation of rabbit antiserum against the rough strain CU1000. Whole cells from strain CU1000 were used as the antigen and injected into three adult male New Zealand white rabbits showing no pre-immune cross-reacting titre to the target organism (Poccono Rabbit Farm, Canadensis, PA, USA). Antisera were titred against both CU1000 and CU1060 using immunofluorescence microscopy. Rabbits achieving a serum titre of greater than 1:2560 against CU1000 antigens were bled. IgG was prepared from decomplemented serum. Titres to strain CU1060 were at least 16-fold less than those achieved for the clinical isolate CU1000. Strain CU1060 was used to adsorb antigens common to both strains, resulting in a polyclonal antiserum with strong specificity for CU1000 (Fine et al., 1996).

Electrophoretic and Western blot analysis of polypeptides. CU1000 and CU1060 were grown as described above. Comparisons were made of whole cells and a supernatant extract derived from whole cells. Whole-cell concentrations were based on optical density and adjusted for equivalence. Supernatant concentrations were estimated for protein by means of the Bio-Rad protein assay. Equivalent protein in the $130-170 \mu \mathrm{g} \mathrm{ml}^{-1}$ range was used. For whole cells, $100 \mu \mathrm{l}$ samples of the adjusted stock suspensions of either CU1000 or CU1060 were pelleted at $14000 \mathrm{~g}$. Supernatant fluid was removed and this whole-cell preparation was resuspended in $100 \mu \mathrm{l}$ SDS loading buffer (Laemmli, 1970). For supernatant preparations, whole cells were resuspended, subjected to vortex agitation at maximum speed for $10 \mathrm{~min}$ to shear surface structures and centrifuged for $30 \mathrm{~min}$ at $10000 \mathrm{~g}$. The supernatant was removed and centrifuged for $10 \mathrm{~min}$ at $14000 \mathrm{~g}$. The resulting supernatant preparation was removed, dried under vacuum and resuspended in $100 \mu$ SDS loading buffer. In addition, a $10 \%$ ammonium sulfate precipitation was performed on the supernatant fraction, an extract from the cell surface. Both whole-cell and supernatant preparations were dissolved in loading buffer, boiled for $30 \mathrm{~min}$ and pelleted at $14000 \mathrm{~g}$ for $30 \mathrm{~min}$ prior to gel loading. Fifteen microlitres of this supernatant was applied to an $18 \%$ SDS polyacrylamide running gel (Laemmli, 1970). A 3\% stacking gel and a discontinuous buffer system was used.

Western blotting was performed on proteins derived from SDS polyacrylamide gels and transferred to nitrocellulose in a Tris/glycine SDS buffer system (Towbin et al., 1979). The BioRad Protoblot AP Western Detection Kit (Bio-Rad) was used to visualize transferred proteins. Western analysis of surfacerelated proteins was performed with rabbit antiserum made to CU1000 previously adsorbed with the smooth strain, CU1060, to provide rough specific antiserum. Dot blot determinations, using antigens from supernatant fluids of CU1000 and CU1060, were used to determine that a titre of $1: 2000$ of the adsorbed antiserum was appropriate for Western Blot analysis. This adsorbed antiserum was used as the primary antiserum and a goat anti-rabbit IgG at a 1:7500 dilution was used as the secondary antibody.

LPS profiles and Limulus activity of CU1000 and CU1060. Overnight cultures of $A$. actinomycetemcomitans strains CU1000 and CU1060 were pelleted, resuspended in $2 \mathrm{ml}$ $0 \cdot 15 \mathrm{M}$ PBS, sonicated, adjusted to an approximate $\mathrm{OD}_{560}$ of 0.8 and repelleted. The final pellet was resuspended in 200-300 $\mu \mathrm{l}$ lysing buffer containing $2 \%$ SDS, $4 \% \quad 2-$ mercaptoethanol, $10 \%$ glycerol, $1 \mathrm{M}$ Tris/ $\mathrm{HCl}, \mathrm{pH} 6 \cdot 8$, and bromophenol blue, heated at $100^{\circ} \mathrm{C}$ for $5 \mathrm{~min}$ and stored at $4{ }^{\circ} \mathrm{C}$. To digest bacterial proteins, $25 \mu \mathrm{g}$ proteinase $\mathrm{K}$ in $10 \mu \mathrm{l}$ lysing buffer was added to $50 \mu \mathrm{l}$ sample. The mixture was heated at $55^{\circ} \mathrm{C}$ for $1 \mathrm{~h}$ and diluted $1: 2$ prior to electrophoresis. Ten microlitres of this sample was removed, boiled for $5 \mathrm{~min}$ in a water bath, added to a $14 \%$ SDS resolving gel and a $3 \%$ SDS stacking gel and run at a constant voltage of $200 \mathrm{~V}$ for $5 \mathrm{~h}$ (Apicella et al., 1994). Gels were fixed with a solution of $40 \%$ ethanol and $5 \%$ acetic acid, washed in $\mathrm{dH}_{2} \mathrm{O}$ and stained with ammoniacal silver (Tsai \& Frasch, 1982).

Initial experiments to determine endotoxin levels of CU1000 and CU1060 were performed using sonicated cell extracts and the Limulus lysate end point clotting assay (Cape Cod Associates). In subsequent experiments, $45 \%$ phenol/water preparations were made of cell suspensions of CU1000, CU1060, Y4 and E. coli. The water phase was removed and subjected to a second extraction with an equal volume of $90 \%$ phenol (Westphal \& Jann, 1965). This phenol/water mixture was heated at $100^{\circ} \mathrm{C}$ for $15 \mathrm{~min}$. Phenol-treated cell extracts were centrifuged and the water phase removed and serially diluted in pyrogen-free water for subsequent testing. Protein concentrations of starting cell suspensions were determined using the Bio-Rad protein assay so that Limulus levels could be related to activity per protein concentration of starting material. Dilutions $\left(10^{-1}-10^{-10}\right)$ of phenol/water extracts were distributed in pyrogen-free Eppendorf microfuge tubes for treatment in the Limulus amoebocyte lysate pyrochrome assay (Cape Cod Associates) (Lindsay et al., 1989). Aliquots $(50 \mu \mathrm{l})$ from each dilution were placed in wells of a 96 -well microplate. A negative control of pyrogen-free water and positive controls of $E$. coli endotoxin standards were added to wells in duplicate (standard dilutions were from 0.1 to 0.5 endotoxin units@5ng per endotoxin unit).An equal volume of the Limulus pyrochrome reagent was added to each well and samples were gently agitated and incubated at $37^{\circ} \mathrm{C}$ for $30 \mathrm{~min}$. The reaction was stopped by addition of $10 \mu \mathrm{l}$ acetic acid and samples were read with a microplate reader at $405 \mathrm{~nm}$. Results were compared to a standard curve generated from the E. coli endotoxin standard and expressed as endotoxin units of activity per unit of protein of CU1000 or CU1060 sample. All experiments were repeated on three separate occasions.

Effect of CU1000 and CU1060 on stimulation of fibroblasts to produce collagenase-like proteinase. Broth cultures of $A$. actinomycetemcomitans strains CU1000 and CU1060 were grown as described above. The cells were harvested by centrifugation, washed, resuspended in 10-15 $\mathrm{ml} \mathrm{0 \cdot 15}$ M PBS and sonicated for $12 \mathrm{~min}$ at a power setting of 4 and a duty cycle of $50 \%$ to disrupt cell membranes. The sonic extract was centrifuged for $30 \mathrm{~min}$ at 10000 r.p.m. to obtain a clear supernatant which was used for determination of fibroblast proteinase activation. Strain Y4 (ATCC 43718) was prepared in a manner similar to that of CU1060. E. coli and $P$. gingivalis were grown as described above.

Supernatant fractions were assayed for protein (Bio-Rad). Primary foreskin fibroblasts (FSF) were established and grown in Dulbecco's Modified Eagle Medium (DMEM; Gibco) containing $10 \%$ heat-inactivated foetal calf serum (Sigma) and $1 \times$ penicillin-streptomycin-glutamine (Gibco). Fibroblasts were grown in $75 \mathrm{~cm}^{2}$ tissue culture flasks (Fisher) and incubated for $4-6 \mathrm{~d}$ in a $5 \% \mathrm{CO}_{2}$ atmosphere at $37^{\circ} \mathrm{C}$. For experimentation, cells grown to a confluent state were separated from the floor of the flask by addition of $2 \mathrm{ml}$ trypsin for $1 \mathrm{~min}$ with gentle agitation. Dislodged cells were mixed and transferred in $1 \mathrm{ml}$ aliquots (at a concentration of $4 \times 10^{4}$ cells $\mathrm{ml}^{-1}$ ) to 24 -well falcon tissue culture trays (Fisher) A challenge dose of $100 \mu \mathrm{l}$ derived from each of the bacterial cell extracts and/or a saline control dose of equal volume was added in duplicate to the FSF. Incubation of the FSF and their challenge dose was accomplished in an atmosphere of $5 \%$ $\mathrm{CO}_{2}$ at $37^{\circ} \mathrm{C}$ for $24 \mathrm{~h}$. After incubation, the supernatant was 

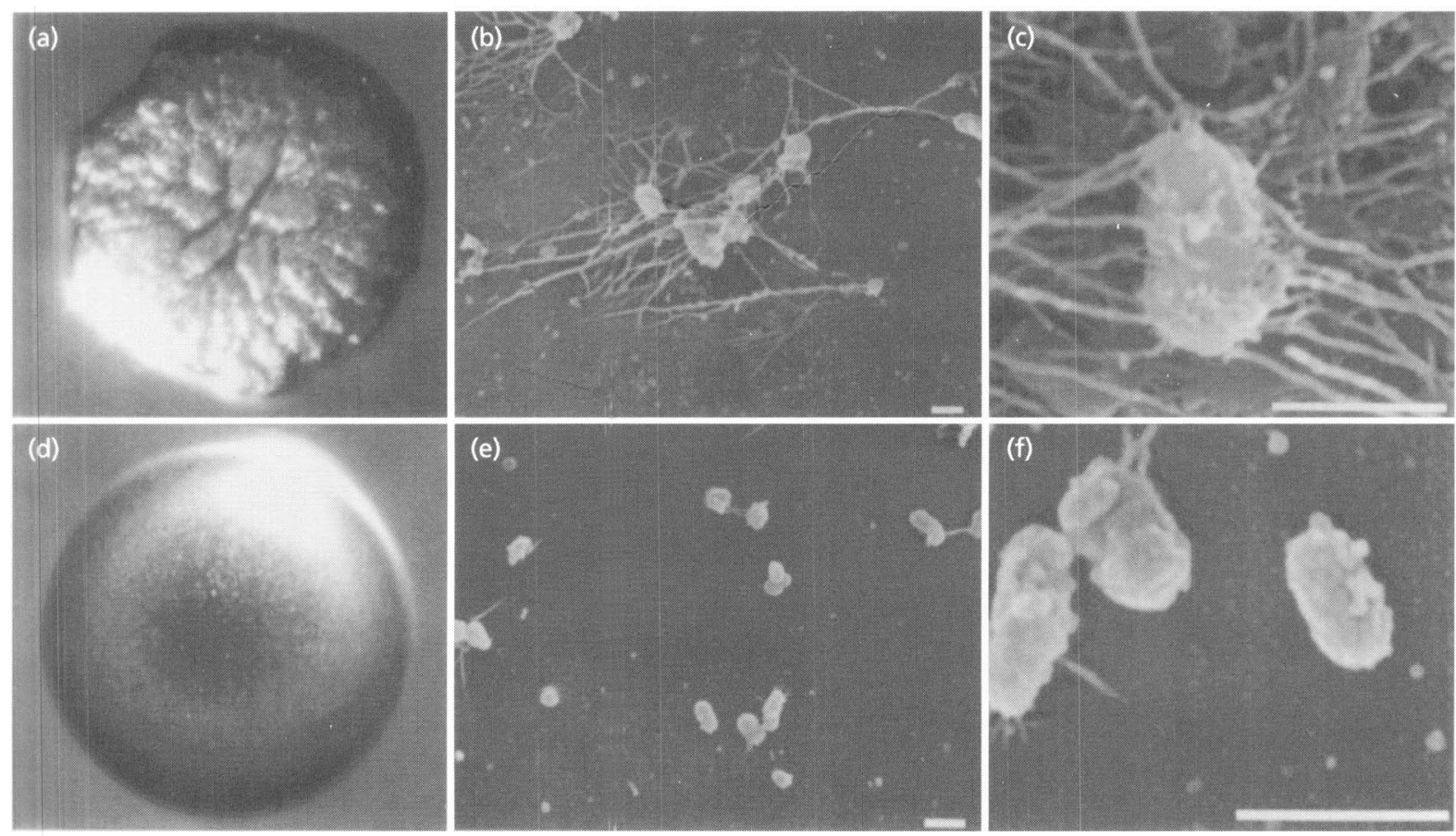

Fig. 1. (a, d) Morphology of Actinobacillus actinomycetemcomitans strains. CU1000 shows a rough-textured, star-positive surface structure (a) whilst CU1060 shows a smooth, star-negative opaque structure (d). (b, c, e, f) Scanning electron micrographs of $A$. actinomycetemcomitans. CU1000 fibrils appear to have joints or kinks along their surface and some appear to extend from cell to cell (b, c). CU1060 does not demonstrate these fibrils, although a few short truncated structures were observed $(e, f)$. Bars, $1 \mu \mathrm{m}$.

removed and assayed for collagenase-like proteinase activity. Supernatants from FSF treated with extracts from CU1000 and CUI()60 were compared to controls that consisted of FSF with no extract, FSF with extracts known to produce little if any collagenase-like/proteinase material (E. coli) and low level collagenase-producing extracts $(P$. gingivalis W-50) to assess the sensitivity of the assay. To test for background collagenase-like/proteinase activity, appropriate concentrations of extract material derived from the bacteria in question was added to the test material in the absence of FSF. Proteinase/collagenase-like activity was determined by means of a substrate consisting of hide powder linked to Remazol brilliant blue (Rinderknecht et al., 1968). In our modification of the assay, $5 \mathrm{mg}$ hide powder was added to $4.9 \mathrm{ml} 0.05 \mathrm{M}$ Tris/HCl buffer, $\mathrm{pH} 7.8$ (Trizma $\mathrm{HCl}$; Sigma). To determine the sensitivity of the reaction and to develop a standard curve, $100 \mu \mathrm{l}$ volumes of dilutions of pure type VII collagenase $\left(6 \cdot 25-50 \mu \mathrm{g} \mathrm{ml}^{-1}\right)$ (Sigma cat. no. C 0773) were added to the hide powder reagent. The blue colour released into the supernatant was measured by spectrophotometry at $A_{595}$. Calculation of the bacterial extract-induced FSF enzyme activity was extrapolated from data obtained from calculations of enzyme activity derived from standard curves. Tubes $(1.5 \times 15 \mathrm{~cm})$ containing mixtures of hide powder and collagenase or extract material were incubated at $37^{\circ} \mathrm{C}$ for $30 \mathrm{~min}$ with agitation at $5 \mathrm{~min}$ intervals. Tubes were cooled in ice and contents were filtered through Whatman No.1 filter paper. Filtrates were assayed spectrophotometrically at $A_{595}$ and results were reported in $\mu \mathrm{g}$ enzyme activity ( $\mu \mathrm{g}$ protein added to the hide powder $)^{-1}$. Aminophenylmercuric acetate (APMA) was added to extract-treated FSF at a final concentration of $1.5 \mathrm{mM}$ in Tris/ $\mathrm{HCl}$ buffer, $\mathrm{pH} 7.5$. This treatment was used to activate latent collagenase-like pro- teinase activity produced by FSF. The APMA/FSF cell mixture was incubated for $2 \mathrm{~h}$ at $37^{\circ} \mathrm{C}$ in an atmosphere of $\mathrm{CO}_{2}$ and the supernatant removed for subsequent determination of enzyme activity in APMA-treated and untreated cells (Golub et al., 1990; Sorsa et al., 1992). Under these assay conditions only fibroblast-derived proteinase activity is enhanced by addition of APMA (Golub et al., 1990; Sorsa et al., 1992). To determine the effect of heat treatment on $A$. actinomycetemcomitans activation of fibroblasts, extracts from CU1000 were divided into two equal aliquots; one heated to $100{ }^{\circ} \mathrm{C}$ for $20 \mathrm{~min}$, the other kept at room temperature. Equal concentrations of heat-treated and untreated extracts were incubated with $1 \mathrm{ml}$ FSF cultures for $24 \mathrm{~h}$. Supernates were removed and assayed for enzymic activity. Estimates of the molecular mass of the collagenase-like/proteinase-stimulating factor were assessed by passing extracts from $A$. actinomycetemcomitans through molecular mass exclusion columns of $<10,<30$ and $<100 \mathrm{kDa}$ (Microcon/Amicon). Fractions obtained in this manner were applied to the FSF cultures and tested for their ability to activate fibroblasts to produce collagenase-like proteinase material.

\section{RESULTS}

General features of a clinical isolate of $A$. actinomycetemcomitans and its isogenic smooth variant

Colony morphology. Fresh clinical isolates of A. actinomycetemcomitans were obtained and appeared as raised, convex, raisin-textured colonies that left a 'footprint' in the agar after removal. The colonies were 

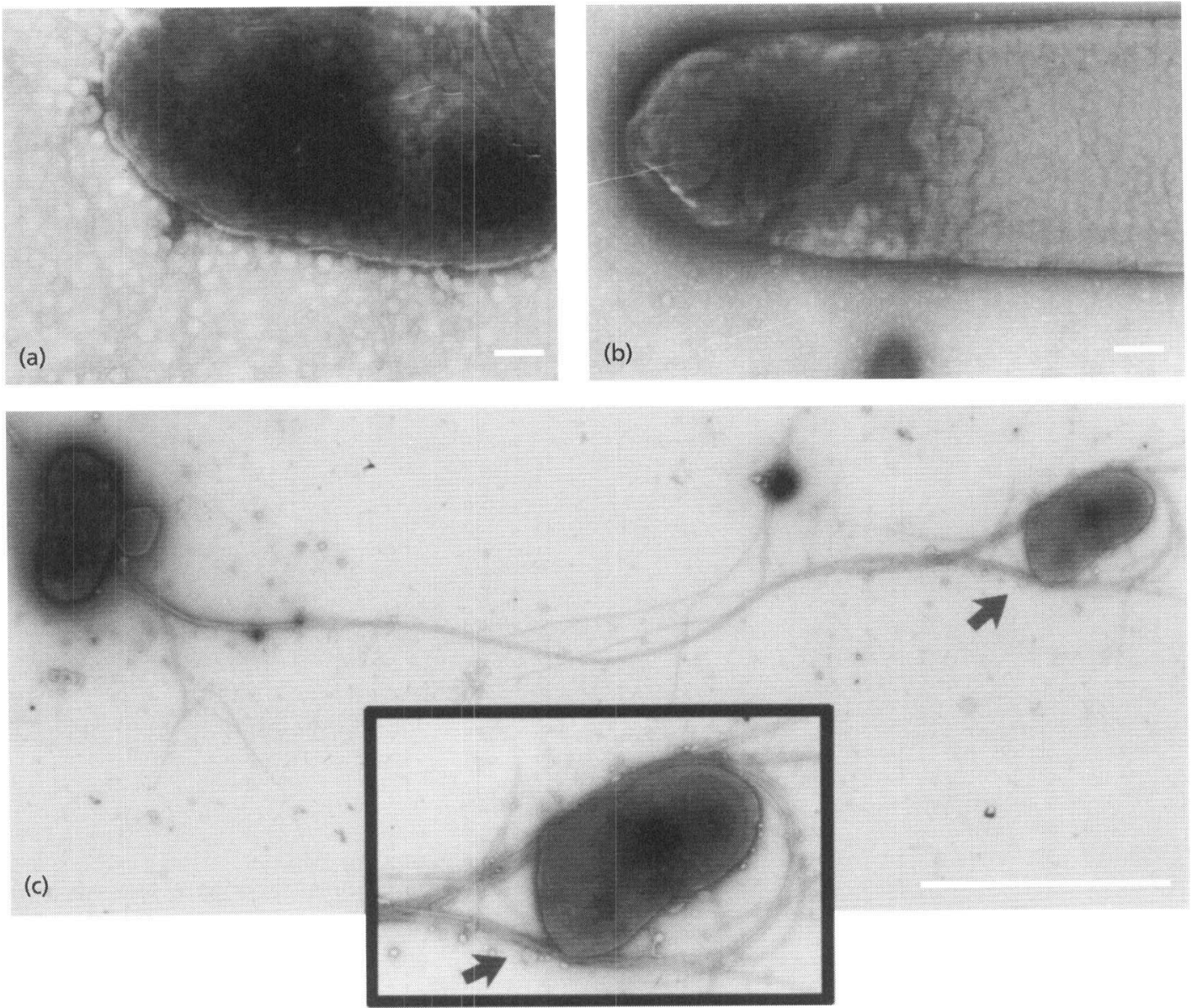

Fig. 2. Transmission electron micrographs of negatively stained $A$. actinomycetemcomitans. (a) CU1000 cells show thin flexible fimbriae that extend from the cell surface. These appendages were not seen on CU1060 cells (b). (c) Bundle-type fimbriae of CU1000. Note the length of these polar appendages and possible relationship to cell-to-cell attachment. The insert shows an enlargement of the thick fibrils encircling a nearby bacterium. Bars, $1 \mu \mathrm{m}$.

approximately $1-2 \mathrm{~mm}$ in diameter and had a characteristic central internal star when observed by transmitted light microscopy (Fig. 1a). One such colony was purified by restreaking and named CU1000. It was possible to maintain the rough colony morphology of CU1000 for greater than 65 passages of single colonies on AAGMBV agar. Transfer of these colonies from solid medium to broth resulted in growth of cells that adhered to the glass walls of the test tube or the plastic walls of the culture flask. Binding of the bacteria was so tenacious that efforts to subculture the organism by sampling the broth without agitation or scraping routinely failed to produce growth. However, when CU1000 was grown repeatedly in broth culture, eventually the cultures would produce a turbid mixture of adherent and non-adherent cells. Aliquots taken from the centre of these broth cultures and plated on AAGM agar demonstrated raised, smooth, translucent colonies that lacked an internal star. Smooth colonies with the same growth properties in broth appeared rarely and spontaneously during growth of CU1000 on solid medium. One such variant was named CU1060 (Fig. 1d).
This smooth strain showed the same properties as those derived from broth cultures.

Electron microscopic analysis of rough (CU1000) and smooth (CU1060) strains. CU1000 and CU1060 were examined by scanning electron microscopy (SEM) and transmission electron microscopy (TEM). Scanning electron micrographs of CU1000 (Fig. 1b, c) revealed individual cells within a dense matrix of thick fibrils. Multiple fibrils extended from each cell with the distal ends seemingly attached to the surface. The fibrils gave the appearance of having joints or kinks along their length and showed evidence of branching. In some cases, these fibrils appeared to be distributed around the entire cell. When found in this configuration, these structures resembled the bundle forming pilin seen in enteropathogenic E. coli (Nataro et al., 1992). The long fibrils were absent from cells from the smooth strain CU1060, although short truncated structures could be observed on some of the cells (Fig. 1e, f). The most striking structures observed by TEM of negatively stained cells were long, densely bundled fimbriae-like appendages that protruded from the surface of rough strain CU1000 (Fig. 2c). No such 


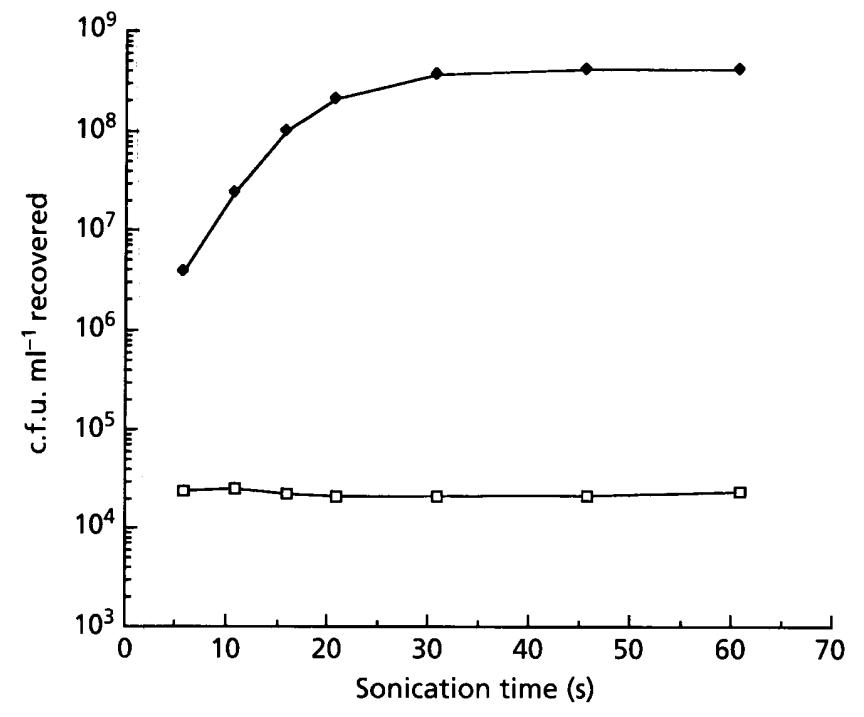

Fig. 3. Attachment of CU1000 ( $\diamond)$ and CU1060 ( $\square)$ to SHA. Sonication was used to dislodge cells from SHA. CU1000 binds several thousand times more than CU1060 (the ratio of bound/free cells was $0.283 \pm 0.03$ for CU1000 compared to $0.000011 \pm 0.000008$ for CU1060).

structures were observed on cells of smooth strain CU1060 (Fig. 2b). The long fibrils seen on the surface of CU1000 by SEM examination may represent the bundled fimbriae observed by TEM (Fig. 2c).
Autoaggregating tendencies of CU1000 and CU1060. Autoaggregation was defined as the ability of cells to form aggregates or clumps that settled to the bottom of a liquid broth suspension. Sonication was used to disaggregate and disperse clumps of cells to produce a relatively homogeneous suspension so that reaggregation could be determined in a quantitative manner over time. Incremental increases in the time of sonic dispersion were used to increase the time required for reformation of aggregates. Results for CU1000 demonstrated a linear relationship between the length of time used for sonic dispersion of clumped cells and the time required for reaggregation. The sonication times used correspond with reaggregation times as follows: $5 \mathrm{~s}$ sonication resulted in a settling time of $24 \mathrm{~min} ; 15 \mathrm{~s}$ resulted in a reaggregation time of $66 \mathrm{~min} ; 30 \mathrm{~s}$ resulted in a reaggregation time of $102 \mathrm{~min} ; 45 \mathrm{~s}$ resulted in a reaggregation time of $156 \mathrm{~min} ; 60 \mathrm{~s}$ resulted in a reaggregation time of $186 \mathrm{~min}\left(r^{2}\right.$ value of 0.989$)$. In contrast, the smooth strain CU1060 did not reaggregate under any conditions. All experiments were performed in duplicate. Results obtained in these studies were critical for the remaining experiments.

\section{Comparison of virulence properties of the two isogenic strains}

Adherence to SHA. CU1000 and CU1060 were tested for their ability to adhere to SHA. Adherence was de-

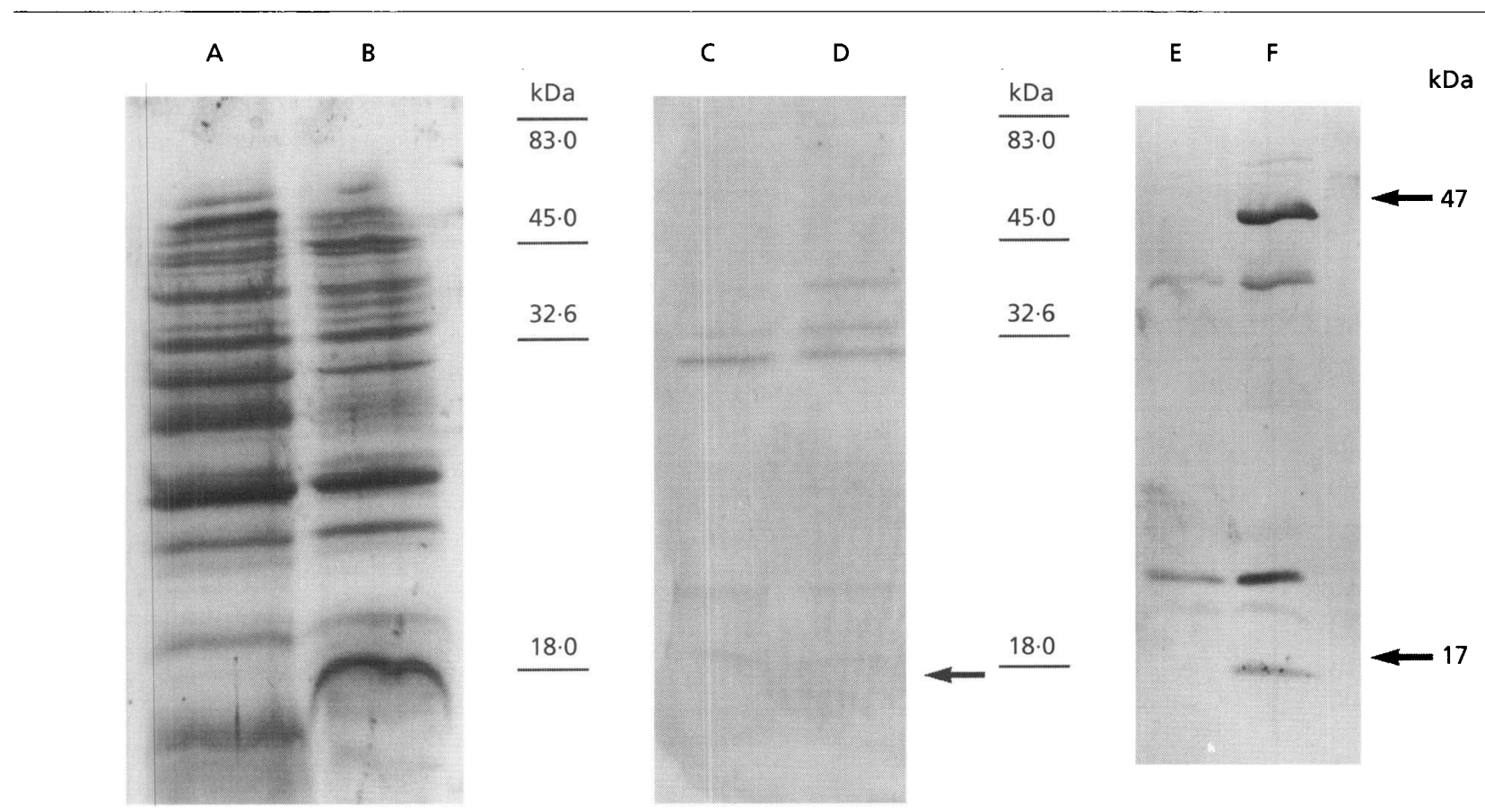

Fig. 4. SDS-PAGE and Western blotting analysis of CU1000 and CU1060. Cell-surface-extracted antigens are seen in lanes $A$ and $B$. An ammonium sulfate preparation of the cell-surface-extracted material is seen in lanes $C$ and $D$. Lanes $A$ and $C$, CU1060; lanes B and D, CU1000. A $17 \mathrm{kDa}$ band with an anomalous shape derived from CU1000 is seen in lane B. A Western blot of an ammonium sulfate preparation derived from CU1000 and CU1060 (lanes E and F) shows bands at approximately 17 and $47 \mathrm{kDa}$ that are unique to CU1000 (lane F, arrows). Bands at 20, 23 and $39 \mathrm{kDa}$ appear common to both strains. The patterns illustrated are representative of gels that were run a minimum of three times. 
A

B

C

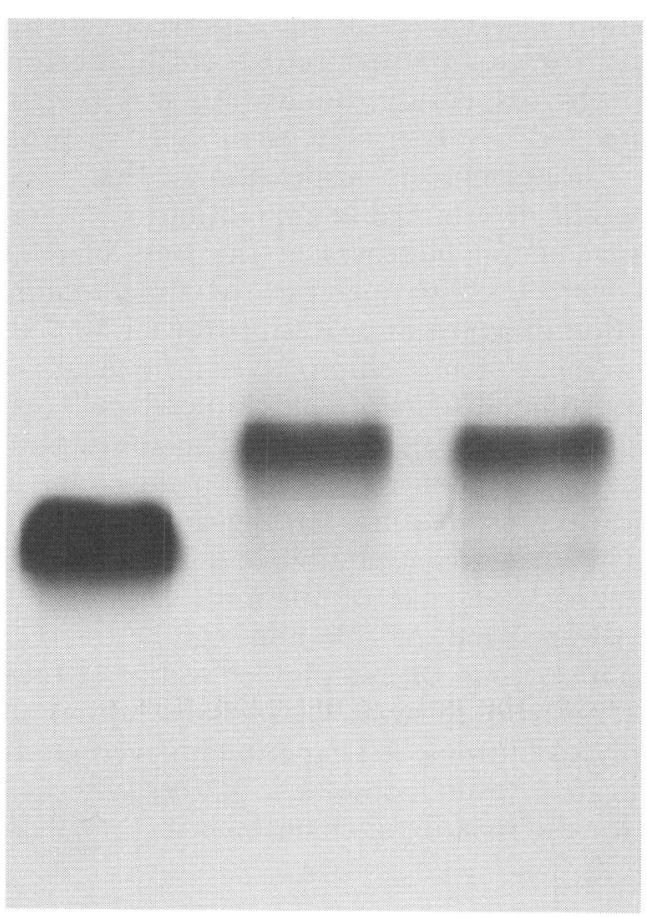

Fig. 5. LPS patterns and activity of CU1000 and CU1060. Gel comparing CU1000 to CU1060. Lanes: A, control; B, CU1000; C, CU1060. The patterns of CU1000 and CU1060 are different. CU1060 appears to have a degraded secondary band.

Table 1. Stimulation of fibroblasts to produce collagenase-like activity

\begin{tabular}{|lc|}
\hline Bacterial extract & $\begin{array}{c}\text { Collagenase-like proteinase activity } \\
\text { ( } \boldsymbol{\mu g} \text { activity/ } \boldsymbol{\mu g} \text { extract protein } \mathrm{ml}^{-1} \text { ) }\end{array}$ \\
\hline Control (FSF only) & $0 \pm 0$ \\
E. coli INVF' $\alpha$ & $0.006 \pm 0.007$ \\
$P$. gingivalis & $0.033 \pm 0.015$ \\
ATCC 53978 & $0 \cdot 215 \pm 0.017^{*}$ \\
CU1000 & $0.080 \pm 0.026$ \\
CU1060 & $0.061 \pm 0.020$ \\
\hline
\end{tabular}

* Significant by ANOVA analysis and Scheffé $F$ testing at $P<0.05$.

termined by incubation of beads with known and equivalent quantities of CU1000 and CU1060. Supernatants containing bacteria removed after sonication of the bead/bacterial complex for different time periods were titred on AAGM agar to count the colonies. Beads were sonicated for times ranging from 0 to $60 \mathrm{~s}$ to estimate attached bacteria dislodged from the beads. The zero time counts contained bacteria in the supernatant before sonication was started. These counts were used to assess unbound cells. Counts obtained after $60 \mathrm{~s}$ sonication were used to estimate the maximum number of bound cells. In the case of CU1060, few if any cells were bound to SHA (Fig. 3). In contrast, the rough clinical isolate CU1000 attached avidly and at high levels to SHA. The plateau point required for maximal removal of cells from SHA was approximately $30 \mathrm{~s}$ for CU1000. There was little difference between the number of cells attached at zero time and at $60 \mathrm{~s}$ following sonic removal in the case of CU1060, thus no plateau point could be determined. Binding of CU1000 to HA was reduced by pretreatment with either saliva or BSA (data not shown). BSA pretreatment reduced binding of CU1000 to HA minimally ( $2 \%)$; however, reduction by saliva pretreatment was substantial $(87 \%$ ) (HA data not shown). Since $A$. actinomycetemcomitans lives in a serum environment, binding to BSA-coated HA may be more in keeping with in vivo conditions.

Polypeptide and serological differences between the two strains. Coomassie-blue-stained SDS-polyacrylamide gels of whole-cell extracts and supernatants derived from CU1000 and CU1060 revealed few qualitative differences between the two strains. The most consistent finding was the demonstration of a $17 \mathrm{kDa}$ protein band with an anomalous shape present in the cell-surface extract derived from the clinical isolate CU1000 that was not seen in CU1060 (Fig. 4, lane B). A further purification was performed by addition of $10 \%$ ammonium sulfate to the supernatant to yield a precipitate of the crude cell extract. While this purification did not yield any differences in Coomassie-blue-stained gels (Fig. 4, lanes C, D), Western blot analysis of these proteins highlighted the intensity of the two reactive areas that appeared to be unique to CU1000, the 47 and $17 \mathrm{kDa}$ bands (Fig. 4, lane $\mathrm{F}$ arrows). The exact nature of the differences in these surface-related proteins is currently under study.

LPS profiles and Limulus activity of CU1000 and CU1060. Electrophoretic profiles of LPS derived from strains CU1000 and CU1060 were distinct (Fig. 5, lanes B, C). In all cases the LPS gels showing CU1000 banding patterns appear to illustrate tighter banding while those from CU1060 appear to show multiple bands that are more diffuse. These differences were consistently reproduced in three separate gels comparing CU1000 to CU1060. Phenol/water-extracted LPS from CU1000 and CU1060 differed in their Limulus amoebocyte lysate reactivity, LPS from strain CU1000 exhibiting approximately 100 times greater reactivity than CU1060 $\left[293.50 \pm 47.73\right.$ endotoxin units $(\mu \mathrm{g} \text { protein })^{-1}$ for CU1000 compared to $3 \cdot 29 \pm 0.33$ endotoxin units $(\mu \mathrm{g}$ protein) $^{-1}$ for CU1060]. The Limulus activity of the CU1060 compares favourably to levels of crude endotoxin-like material seen in experiments with strain Y4 and E. coli (Nishihara et al., 1986).

Effect of CU1000 and CU1060 on fibroblast collagenase-like activity. In all experiments extract material from CU1000 stimulated FSF to produce a collagenase-like/proteinase activity. Extract material from each of the bacterial strains at concentrations of $10-250 \mu \mathrm{g}$ material $\mathrm{ml}^{-1}$ 
Table 2. Preliminary characterization of fibroblast-inducing factor produced by CU1000

\begin{tabular}{|c|c|c|}
\hline Treatment & $\begin{array}{l}\text { Collagenase-like proteinase activity } \\
\left(\mu \mathrm{g} \text { activity/ } \mu \mathrm{g} \text { extract protein } \mathrm{ml}^{-1}\right)\end{array}$ & Relative activity \\
\hline Untreated & $0 \cdot 26 \pm 0 \cdot 01$ & 100 \\
\hline Heat-treated & $0 \cdot 27 \pm 0 \cdot 01$ & $104^{*}$ \\
\hline APMA added $\dagger$ & $0 \cdot 49 \pm 0 \cdot 02$ & 188 \\
\hline Molecular mass exclusion $>10 \mathrm{kDa} \ddagger$ & $0 \cdot 008 \pm 0 \cdot 003$ & 0 \\
\hline Molecular mass exclusion $>30 \mathrm{kDa} \ddagger$ & $0 \cdot 33 \pm 0 \cdot 03$ & 127 \\
\hline Molecular mass exclusion $>100 \mathrm{kDa}$ & $0 \cdot 29 \pm 0 \cdot 03$ & $112 \mathbb{S}$ \\
\hline
\end{tabular}

*No effect.

† Stimulates fibroblasts to produce more enzyme.

$\ddagger$ Molecular mass range of fibroblast-inducing factor $(10-30 \mathrm{kDa})$; heat insensitive.

\$Equivalent to background level as seen when fibroblasts are unstimulated.

were added to FSF and in each case CU1000 produced a statistically significant level of proteinase/collagenaselike activity in the FSF supernatant compared to all other material added. In all cases results were compared to proteinase/collagenase levels of the bacterial extracts alone and to the culture supernatants containing FSF alone, FSF plus E. coli (negative control) and FSF plus $P$. gingivalis (low-positive control). Table 1 shows data representative of these experiments and shows the level of collagenase-like/proteinase activity resulting from the addition of $60 \mu \mathrm{g}$ bacterial extract material $\mathrm{ml}^{-1}$ to the FSF culture $(P<0.05)$. Data in Table 2 indicate that the stimulatory material induced by CU1000 is heatinsensitive, has a molecular mass between 30 and $100 \mathrm{kDa}$, and appears to be derived from fibroblasts, since addition of APMA increased latent fibroblast activity while addition of APMA to the material derived from CU1000 in the absence of fibroblasts had no effect. All quantitative data presented in this section are shown as means $\pm S D$ and are derived from experiments where samples were run in duplicate a minimum of three times.

\section{DISCUSSION}

Initial observations indicated that the clinical strain (CU1000) and its variant (CU1060) demonstrated similar characteristics to key attributes previously described for A. actinomycetemcomitans (Slots, 1982a). The clinical isolate appeared as a rough, star-positive colony that demonstrated fibrillar extensions, antigenic patterns and attachment properties consistent with characteristic features reported for A. actinomycetemcomitans isolates (Scannapieco et al., 1987; Slots, 1982a). The laboratory strain appeared as a smooth colony with no fibrils, with a reduced and different pattern of proteins and minimal attachment. It is unclear whether previous reports have studied clinical and laboratory variant strains obtained from a young patient with active disease (Inouye et al., 1990). Nevertheless, clear differences between clinical isolates and laboratory strains have been described before (Rosan et al., 1988). In spite of these differences, only a few studies include clinical isolates in their evaluation of the pathogenic properties of A. actinomycetemcomitans.

\section{Rationale and methodology for studies using stably maintained clinical isolates}

There are at least three possible explanations for the failure to include clinical isolates in studies of $A$. actinomycetemcomitans. First, it has been proposed that it is difficult to consistently maintain the strain in its clinical state. This conclusion is based on reports that the clinical isolate loses its most obvious characteristics of fimbriae and adherence on repeated passage (Inouye et al., 1990; Rosan et al., 1988; Scannapieco et al., 1987). Second, the clinical isolate aggregates and the resulting clumped cell mass makes it difficult to achieve a homogeneous suspension of cells for reproducible quantitative experimentation (Rosan et al., 1988; Wyss, 1989). Finally, since only a few differences between clinical isolates and laboratory variants have been described to date, the potential importance of these differences may have been overlooked (Zambon, 1985; Zambon et al., 1988). This report addresses these issues directly in an effort to establish the relevance of the well preserved clinical phenotype. We agree that conversion of rough, star-positive, adherent, fimbriated colonies to smooth, star-negative, non-adherent, afimbriate colonies on subculture of $A$. actinomycetemcomitans can be readily accomplished (Rosan et al., 1988; Scannapieco et al., 1987). However, we show here that it was possible to maintain the phenotype of the original clinical isolate indefinitely. In our hands, the rough phenotype is maintained by passage from solid medium to solid medium. In contrast, repeated passage of isolates in broth enriches for smooth, star-negative, non-adherent variants. Five clinical isolates have been tested thus far and all remained rough and star-positive when passed on agar after many subcultures (more than 60) following clinical isolation (data not shown; Fine $e t$ al., 1995b, 1996). We have also been able to obtain smooth variants from each of these isolates (data not shown; Fine \& Furgang, 1997; Fine et al., 1995b, 1996). These 
phenotypes have been preserved by freezing at $-80^{\circ} \mathrm{C}$ for long-term storage for over 4 years. We have not yet detected reversion of smooth variants to the rough, adherent phenotype on artificial medium in vitro. Moreover, we have not observed conversion of the smooth strain to a rough phenotype or vice versa in studies where rifampin-labelled strains have been implanted and maintained in the oral cavity of SpragueDawley rats for 8 weeks (Goncharoff et al., 1996). The ability of clinical isolates to autoaggregate has been reported although no quantitative approach to this characteristic has been documented (Rosan et al., 1988). We have developed a timed reaggregation assay in which we demonstrate the effect of low-pulse sonication on the disassociation of cell clumps. Using this assay we were able to show that a $30 \mathrm{~s}$ sonication does not affect cell viability and visible reaggregation takes as long as $1.5 \mathrm{~h}$. This approach yielded reproducible cell density readings for at least $30 \mathrm{~min}$ following a $15 \mathrm{~s}$ sonication so that quantitative experimentation could be performed. With these conditions at hand we began to explore a series of A. actinomycetemcomitans putative virulence traits that had not previously been studied by comparing CU1000 to CU1060.

\section{Comparison of presumptive virulence traits of clinical isolates and their laboratory variants}

Our experiments included comparison of CU1000 and CU1060 with respect to presumed 'surface-related' features, including attachment properties, stimulation of immune responsiveness and tissue-destructive traits. The rough strain, CU1000, displayed the properties of attachment to SHA, whereas the smooth variant, CU1060, did not. This attachment to SHA was so outstanding that we compared the binding of CU1000 to Streptococcus gordonii G9B, a pioneer colonizing species and found that CU1000 attached in greater numbers with greater avidity and in a pattern that resembled a Pseudomonas aeruginosa-like biofilm (Fine et al., 1995a; Hoyle et al., 1993). Moreover, pretreatment of HA with BSA minimally reduced binding of CU1000 ( $2 \%$ reduction). Since serum is more representative of the medium that $A$. actinomycetemcomitans encounters in its natural environment, binding and retention to serum-coated surfaces could be an important initial virulence trait for establishment of this organism in the oral cavity and this requires further study.

Comparison of the two strains in their ability to stimulate immune responsiveness was initiated by estimating differences in Western Blot profiles of transferred surface proteins. A $17-18 \mathrm{kDa}$ protein derived from CU1000 appeared as a prominent surface antigen in Western Blot analysis when the two strains were compared. A further purification of crude cell extract material from CU1000 increased the intensity of this band and revealed a second distinct band in the $47 \mathrm{kDa}$ region. In addition, preliminary observations have revealed that the $17-18 \mathrm{kDa}$ protein in strain CU1000 is reactive with antisera from juvenile periodontitis patients but not with sera from healthy controls (not shown). These findings suggested that the periodontal patient was seeing an antigen on the surface of CU1000 that might have been missing or in low concentration in the laboratory variant strains. Much of the literature related to the pathogenic potential of A. actinomycetemcomitans has been based on virulence factors derived from the laboratory strain $\mathrm{Y} 4$ or other frequently grown laboratory strains. Moreover, much of the antibody data obtained from patients afflicted with periodontal disease have been tested using $\mathrm{Y} 4$ and other laboratory strain(s) to provide the target antigens. In light of this report and those of others (Inouye et al., 1990; Saito et al., 1992; Wyss, 1989), this approach may miss useful information about patient responses. In addition, we have detected at least one other antigen, a $47 \mathrm{kDa}$ protein, seen when clinical isolates were compared to smooth variants typical of laboratory strains. The use of well defined clinical isolates as a source of target antigens to detect patient antibody responses appears to be warranted (Saito et al., 1993; Wyss, 1989).

Like other effective pathogens $A$. actinomycetemcomitans requires several distinct and well choreographed virulence traits that enable the organism to cause destruction of host tissue (Finlay \& F Falkow, 1989). One prominent virulence trait attributed to many Gram-negative pathogens is the presence of highly reactive and tissue-destructive endotoxin or LPS (Rosen, 1961). LPS patterns can be determined by gel electrophoresis and endotoxin activity can be estimated by the Limulus lysate assay (Apicella et al., 1994; Lindsay et al., 1989). Comparison of LPS banding using silver-stained SDS-PAGE indicated that CU1000 and CU1060 have different LPS patterns. Preliminary chemical analyses have confirmed the results obtained by gel electrophoresis (data not shown). When tested for activity using either the crude sonicated form of the organisms, or a modified phenol/water extract, it was apparent that CU1000 had significantly more Limulus activity per $\mu \mathrm{g}$ starting protein than either CU1060, Y4 or an E. coli standard. Limulus activity has often been used as a measure of B cell mitogenicity and cell cytotoxicity and is thought of as a surrogate for endotoxin activity (Tew et al., 1989). These findings suggest that clinical isolates possess a significantly greater potential for LPS-related pathogenicity than their laboratory homologues. A second prominent virulence trait often associated with the destruction of periodontal tissue and attributed to another well studied periodontal pathogen, $P$. gingivalis, is the production of tissue-destructive enzymes such as collagenase (Mayrand \& Grenier, 1985). Previous reports have suggested that $A$. actinomycetemcomitans has collagenase activity (Robertson et al., 1982). Using our assay CU1000, CU1060 and Y4 did not produce collagenase. However, our results did show that CU1000, unlike CU1060 or Y4, stimulated FSF to produce an enzyme that degraded connective tissue. These findings agree with some reports (Sorsa et al., 1992) but appear to contradict earlier reports indicating that $A$. actinomycetemcomitans causes fibroblast cyto- 
toxicity and decreased metabolic activity (Shenker et al., 1982; Stevens et al., 1983). However, reports on cytotoxicity did not characterize fibroblast collagenase activity, nor did they use clinical isolates. The factor that induces fibroblast activity is heat-insensitive and has a molecular mass range between 30 and $100 \mathrm{kDa}$ that could suggest a low molecular mass LPS. More work needs to be done to better characterize this potential virulence trait.

In conclusion, findings suggest that there are a number of traits that CU1000 possesses that are either absent or significantly depressed in the isogenic laboratory variant. It is our assumption that the lack of interest in the clinical form of A. actinomycetemcomitans stems from its fragile stability, its characteristic of clumping or autoaggregation and the limited number of differences reported between the clinical and laboratory state of this well recognized oral pathogen. In this study, we have described methods of maintenance and preservation of the clinical characteristics of the organism. In addition, we have described methods to disaggregate clumped cells for a period of time sufficient to perform quantitative studies. Using these methods we were able to show that our isolate possessed the same phenotype as those of previously characterized clinical isolates (Inouye et al., 1990; Rosan et al., 1988; Scannapieco et al., 1987). We have also described several characteristics of the clinical isolate that have not been shown previously and compared these properties to a spontaneous laboratory variant/mutant. We therefore conclude that the methods described above for preservation and manipulation of the clinical isolate and its laboratory variant can provide a useful first step for the in depth analysis of virulence traits attributed to this important oral pathogen. This study focused on presumed 'surface-associated' properties related to attachment, immune responsiveness and tissue-destructive activities as they were seen in a parental and variant strain. We found that the clinical isolate in its characteristic rough phenotype displayed several distinctive features that should be important to the colonization and pathogenesis of A. actinomycetemcomitans. However, it is likely that additional phenotypes that include the expression of other putative virulence factors could also be affected in the transformation to the smooth variant. The study of 'isogenic' strains should therefore provide a useful strategy for uncovering potential pathogenic traits for molecular analysis of genes and factors associated with disease.

\section{ACKNOWLEDGEMENTS}

The authors would like to acknowledge Dr Chern Lai, University of Pennsylvania, for his help with the serotyping of CU1000 and CU1060 and Dr Ed Lally, of the same school, for his assistance with the leukotoxin activity classification for CU1000 and CU1060. We would also like to acknowledge the generous gift of antisera from juvenile periodontitis patients from Dr Joe Califano, University of Virginia. In addition we would like to thank Dr M. Apicella and his group at The University of Iowa for his help with the LPS gels in our efforts to determine the difference between LPS content of CU1000 and CU1060

\section{REFERENCES}

Anolik, R., Berkowitz, R. J., Campos, J. M. \& Friedman, A. D. (1981). Actinobacillus endocarditis associated with periodontal disease. Clin Pediatr 20, 653-655.

Apicella, M. A., Griffiss, J. M. \& Schneider, H. (1994). Isolation and characterization of lipopolysaccharides, lipooligosaccharides, and lipid. Methods Enzymol 235, 242-252.

Baehni, P., Tsai, C. C., McArthur, W. P., Hammond, B. F. \& Taichman, N. S. (1979). Interaction of inflammatory cells and oral microorganisms. VIII. Detection of leukotoxic activity of a plaque-derived Gram-negative microorganism. Infect Immun 24, 233-243.

Brogan, J. M., Lally, E. T., Poulsen, K., Kilian, M. \& Demuth, D. R. (1994). Regulation of Actinobacillus actinomycetemcomitans; leukotoxin expression: Analysis of the promoter regions of leukotoxic and minimally leukotoxic strains. Infect Immun 62, 501-508.

Burgher, L. W., Loomis, G. W. \& Ware, F. (1973). Systemic infection to Actinobacillus actinomycetemcomitans. Am J Clin Pathol 60, 412-415.

Clark, W. B., Bammann, L. L. \& Gibbons, R. J. (1978). Comparative estimates of bacterial affinities and absorption sites to hydroxyapatite surfaces. Infect Immun 19, 846-853.

Duguid, J.P. \& Gillies, R. R. (1957). Fimbriae and adhesive properties in dysentery bacilli. J Pathol Bacteriol 74, 397-411.

Fine, D. H. \& Furgang, D. (1997). Actinobacillus actinomycetemcomitans resistance to human lactoferrin killing. J Dent Res 76, 227.

Fine, D. H., Furgang, D., Goncharoff, P., Schreiner, H. \& Figurski, D. (1995a). Salivary effects on binding of adherent Actinobacillus actinomycetemcomitans (Aa) CU1000. J Dent Res 74, 199.

Fine, D. H., Furgang, D., Schreiner, H. C., Goncharoff, P., Charlesworth, J. \& Figurski, D. (1995b). Phenotypic variation in $A$. actinomycetemcomitans: Spontaneous loss of putative virulence factors. J Dent Res 74, 200.

Fine, D. H., Furgang, D., Steinberg, L. \& Korik, I. (1996). Buccal epithelial cell adherence by a clinical Actinobacillus actinomycetemcomitans isolate. J Dent Res 75, 204.

Finkelstein, R. A., Vasil, M. L. \& Holmes, R. K. (1979). Studies on toxinogenesis in Vibrio cholerae. I. Isolation of mutants with altered pathogenicity. J Infect Dis 129, 117-123.

Finlay, B. B. \& Falkow, S. (1989). Common themes in microbial pathogenesis. Microbiol Rev 53, 210-230.

Garner, J. G. (1979). Isolation of Actinobacillus actinomycetemcomitans and Haemophilus aphrophilus at Auckland Hospital. $N$ Z Med J 89, 384-386.

Golub, L. M., Ciancio, S., Ramamurthy, N. S., Leung, M. \& McNamara, T. F. (1990). Low-dose doxycycline therapy: Effect on gingival and crevicular fluid collagenase activity in humans. $J$ Periodontal Res 25, 321-330.

Goncharoff, P., Figurski, D. H., Stevens, R. H. \& Fine, D. H. (1993). Identification of Actinobacillus actinomycetemcomitans: PCR amplification of $l k t A$-specific sequences. Oral Microbiol lmmunol 8, 105-110.

Goncharoff, P., Schreiner, H. C., Chang, K. M., Figurski, D. H. \& Fine, D. H. (1996). An improved rat model for the establishment of Actinobacillus actinomycetemcomitans. J Dent Res 75, abstract 3237. 
Guerina, N. G., Kessler, T. W., Guerina, V. J., Nuetra, M. R., Clegg, H. W., Langermann, S., Scannapieco, F. A. \& Goldman, D. A. (1983). The role of pili and capsule in the pathogenesis of neonatal infection with Escherichia coli K1. J Infect Dis 148, 395-405.

Holt, S. C., Tanner, A. C. \& Socransky, S. S. (1980). Morphology and ultrastructure of oral strains of Actinobacillus actinomycetemcomitans and Haemophilus aphrophilus. Infect Immun 30, 588-600.

Hoyle, B. D., Williams, L. J. \& Costerton, J. W. (1993). Production of mucoid exopolysaccharide during development of Pseudomonas aeroginosa biofilms. Infect Immun 61, 777-781.

Inouye, T., Ohta, H., Kokeguchi, S., Fukui, K. \& Kato, K. (1990). Colonial variation and fimbriation of Actinobacillus actinomycetemcomitans. FEMS Microbiol Lett 57, 13-17.

Kamen, P. R. (1983). Inhibition of keratinocyte proliferation by extracts of Actinobacillus actinomycetemcomitans. Infect Immun 42, 1191-1194.

Kaplan, A. H., Weber, D. J., Oddone, E. Z. \& Perfect, J. R. (1989). Infection due to Actinobacillus actinomycetemcomitans: 15 cases and review. Rev Infect Dis 11, 46-61.

Kellogg, D. S., Peacock, W. L., Deacon, W. E., Brown, L. \& Pirkle, C. I. (1963). I. Virulence genetically linked to clonal variation. $J$ Bacteriol 85, 1274-1279.

Kraig, E., Dailey, T. \& Kolodrubetz, D. (1990). Nucleotide sequence of the leukotoxin gene from Actinobacillus actinomycetemcomitans: homology to the alpha-hemolysin/leukotoxin gene family. Infect Immun 58, 920-929.

Laemmli, U. K. (1970). Cleavage of structural proteins during the assembly of the head of bacteriophage T4. Nature 227, 680-685.

Lally, E. T., Golub, E. E., Kieba, I. R., Taichman, N. S., Rosenbloom, J., Rosenbloom, J. C., Gibson, C. W. \& Demuth, D. R. (1989). Analysis of the Actinobacillus actinomycetemcomitans leukotoxin gene. Delineation of unique features and comparison to homologous toxins. J Biol Chem 264, 15451-15456.

Lindsay, G. K., Roslansky, P. F. \& Novitsky, T. (1989). Single-step, chromogenic Limulus Amebocyte Lysate Assay for endotoxin. $J$ Clin Microbiol 27, 947-951.

Mandell, R. L. \& Socransky, S. S. (1981). A selective medium for Actinobacillus actinomycetemcomitans and the incidence of the organism in juvenile periodontitis. J Periodontol 52, 593-598.

Mayrand, D. \& Grenier, D. (1985). Detection of collagenase activity in oral bacteria. Can J Microbiol 31, 134-138.

Muhle, I., Rau, J. \& Ruskin, J. (1979). Vertebral osteomyelitis due to Actinobacillus actinomycetemcomitans. JAMA 241, 1824-1825.

Nataro, J. P., Deng, Y., Maneval, D. R., German, A. L., Martin, W. C. \& Levine, M. M. (1992). Aggregative adherence fimbria I of enteroaggregative Escherichia coli mediate adherence to HEp-2 cells and hemagglutination of human erythrocytes. Infect Immun 60, 2297-2304.

Newman, M. G., Socransky, S. S., Savitt, E. D., Propas, D. A. \& Crawford, A. (1976). Studies of the microbiology of periodontosis. J Periodontol 47, 373-379.

Nishihara, T., Fujiwara, T., Koga, T. \& Hamada, S. (1986). Chemical composition and immunobiological properties of lipopolysaccaride and lipid-associated proteoglycan from Actinobacillus actinomycetemcomitans. J Periodontal Res 21, 521-530.

Rinderknecht, H., Geokas, M. C., Silverman, P. \& Haverback, B. J. (1968). A new ultrasensitive method for the determination of proteolytic activity. Clin Chim Acta 21, 197-203.

Robertson, P. B., Lantz, M., Marucha, P. T., Kornman, K. S.,
Trummel, C. L. \& Holt, S. C. (1982). Collagenolytic activity associated with Bacteroides species and Actinobacillus actinomycetemcomitans. J Periodontal Res 17, 275-283.

Rosan, B., Slots, J., Lamont, R. J., Listgarten, M. A. \& Nelson, G. M. (1988). Actinobacillus actinomycetemcomitans fimbriae. Oral Microbiol Immunol 3, 58-63.

Rosen, F. S. (1961). The endotoxins of Gram-negative bacteria and host resistance. N Engl J Med 264, 919-923.

Saarela, M., Asikainen, S., Alaluusua, S., Pyhala, L., Lai, C.-H. \& Jousimies-Somer, H. (1992). Frequency and stability of mono- or poly-infection by Actinobacillus actinomycetemcomitans serotypes a, b, c, d or e. Oral Microbiol Immun 7, 277-279.

Saito, A., Hosaka, Y., Nakagawa, T., Yamada, S. \& Okuda, K. (1992). Relative avidity of serum immunoglobulin $G$ antibody for the fimbria antigen of Actinobacillus actinomycetemcomitans in patients with adult periodontitis. Infect Immun 61, 332-334.

Saito, A., Hosaka, Y., Nakagawa, T., Yamada, S. \& Okuda, K. (1993). The significance of serum antibody against surface antigens of Actinobacillus actinomycetemcomitans in patients with adult periodontitis. Oral Microbiol Immun 8, 146-153.

Scannapieco, F. A., Millar, S. J., Reynolds, H. S., Zambon, J. J. \& Levine, M. J. (1987). Effect of anaerobiosis on the surface ultrastructure and surface proteins of Actinobacillus actinomycetemcomitans (Haemophilus actinomycetemcomitans). Infect Immun 55, 2320-2323.

Shenker, B. J., Kushner, M. E. \& Tsai, C.-C. (1982). Inhibition of fibroblast proliferation by Actinobacillus actinomycetemcomitans. Infect Immun 38, 986-992.

Slots, J. (1982a). Salient biochemical characters of Actinobacillus actinomycetemcomitans. Arch Microbiol 131, 60-67.

Slots, J. (1982b). Selective medium for isolation of Actinobacillus actinomycetemcomitans. J Clin Microbiol 15, 606-609.

Sorsa, T., Ingman, T., Suomalainen, K., Haapasalo, M., Konttinen, Y. T., Lindy, O., Saari, H. \& Uitto, V.-J. (1992). Identification of proteases from periodontopathic bacteria as activators of latent human neutrophil and fibroblast-type collagenases. Infect Immun 60, 4491-4495.

Stevens, R. H., Gatewood, C. \& Hammond, B. F. (1983). Cytotoxicity of the bacterium Actinobacillus actinomycetemcomitans extracts in human gingival fibroblasts. Arch Oral Biol 28, 981-987.

Syed, S. A. \& Loesche, W. J. (1972). Survival of human dental plaque flora in various transport media. Appl Microbiol 24, 638-644.

Taichman, N. S., Dean, R. T. \& Sanderson, C. J. (1980). Biochemical and morphological characterization of the killing of human monocytes by a leukotoxin derived from Actinobacillus actinomycetemcomitans. Infect Immun 28, 258-268.

Tew, J., Engel, D. \& Mangan, D. (1989). Polyclonal B-cell activation in periodontitis. J Periodontal Res 24, 225-241.

Towbin, H., Staehelin, T. \& Gordon, J. (1979). Electrophoretic transfer of proteins from polyacrylamide gels to nitrocellulose sheets: Procedure and some applications. Proc Natl Acad Sci USA 76, 4350-4353.

Townsend, T. \& Gillenwater, J. Y. (1969). Urinary tract infection due to Actinobacillus actinomycetemcomitans. JAMA 210, 558.

Tsai, C. C., McArthur, W. P., Baehni, P. C., Hammond, B. F. \& Taichman, N. S. (1979). Extraction and partial characterization of a leukotoxin from a plaque-derived Gram-negative microorganism. Infect Immun 25, 427-439. 
Tsai, C.-M. \& Frasch, C. E. (1982). A sensitive stain for detecting lipopolysaccharides in polyacrylamide gels. Anal Biochem 119, 115-119.

Westphal, O. \& Jann, K. (1965). Bacterial lipopolysaccharides. Extraction with phenol-water and further application of the procedure. Methods Carbohydr Chem 5, 83-91.

Wyss, C. (1989). Selected low-cohesion variants of Actinobacillus actinomycetemcomitans and Haemophilus aphrophilus lack distinct antigens recognized by human antibodies. Arch Microbiol 151, 133-136.

Yuan, A., Yang, P.-C., Lee, L.-N., Chang, D.-V., Kuo, S.-H. \& Luh, K.-T. (1992). Actinobacillus actinomycetemcomitans pneumonia with chest wall involvement and rib destruction. Chest 101 , 1450-1452.

Zambon, J. J. (1985). Actinobacillus actinomycetemcomitans in human periodontal disease. J Clin Periodontol 12, 1-20.

Zambon, J. J., Umemoto, T., De, N. E., Nakazawa, F., Christersson, L. A. \& Genco, R. J. (1988). Actinobacillus actinomycetemcomitans in the pathogenesis of human periodontal disease. Adv Dent Res 2, 269-274.

Received 18 November 1998; revised 16 February 1999; accepted 22 February 1999. 